\title{
Prevalence and related factors of depressive symptoms in hemodialysis patients in northern China
}

\author{
Xiaodan Liu', Xiaoshi Yang², Li Yao', Quan Zhang³, Da Sun', Xinwang Zhu', Tianhua Xu', Qiang Liu \\ and Lining Wang ${ }^{1 *}$
}

\begin{abstract}
Background: To determine the prevalence of depressive symptoms and to explore related factors of depressive symptoms in hemodialysis (HD) patients in northern China.

Methods: We used a cross-sectional research design to recruit 227 chronic kidney disease (CKD) patients who were undergoing HD treatment in northern China during December, 2012 to March, 2013. The Chinese edition of the Center for Epidemiologic Studies Depression (CES-D) was used to measure depressive symptoms. Information on quality of life (QOL), activities of daily living (ADL), social support status, coping style, self-efficacy, ego resiliency and demographic characteristics was all collected by face to face interview. Multivariate logistic regression analysis was used to explore related factors of depressive symptoms.

Results: The prevalence of depressive symptoms among HD patients was $29.1 \%$. Patients with a lower mood have worse ADL and QOL than patients with better mood. Patients with a lower mood have got less social support than patients with better mood, including both family support and outside family support. For coping style, patients with a lower mood were more inclined to choose "acceptance-resignation" coping style than patients with better mood, while the result is opposite in "avoidance" coping style. And patients with a better mood have better selfefficacy and ego resiliency than patients with lower mood. Multivariate logistic regression analyses revealed that $\mathrm{ADL}(\mathrm{OR}=1.124, p=0.002)$, family support $(\mathrm{OR}=0.867, p=0.021)$, "acceptance-resignation" coping style ( $\mathrm{OR}=1.228$, $p=0.022)$, and ego resiliency ( $\mathrm{OR}=0.944, p=0.021)$ were associated with low mood independently.

Conclusions: The prevalence of depressive symptoms is high in CKD patients on HD in northern China. activities of daily living, family support, "acceptance-resignation" coping style and ego resiliency were independently associated with depressive symptoms.
\end{abstract}

Keywords: Depressive symptoms, Hemodialysis patients, Activities of daily living, Social support, Coping style, Ego resiliency

\section{Background}

With the prevalence of chronic kidney disease (CKD) at $10.8 \%$, there are up to 119.5 million patients with CKD in China. A large portion of patients with CKD progress to end-stage renal disease (ESRD), which need renal replacement therapy $[1,2]$. At the end of 2013, the

\footnotetext{
* Correspondence: wanglining5623@gmail.com

1Department of Nephrology, The First Hospital of China Medical University, No.155 North Nanjing Street, Shenyang, Liaoning, People's Republic of China 110001

Full list of author information is available at the end of the article
}

number of patients receiving dialysis was 326,000 in mainland China, which puts a huge burden on patients and the society [3-5].

Depression is a chronic and recurrent illness. Patients with CKD on hemodialysis (HD) have to endure physical discomforts related to their illness and have to face various stresses, family problems, which increasing the risk of depression [6]. The prevalence of depression is higher among patients receiving HD, with estimated rates ranging from 23 to $42 \%$ in the USA and Europe, and $45.9 \%$ in Taiwan [7-11]. Furthermore, clinical depression and 
subthreshold depressive symptoms are strongly associated with poor adherence to treatment, increased mortality and rates of hospitalization [12-16].

Although an association between depression and HD has been strongly suggested, the prevalence and related factors of depressive symptoms among CKD patients on HD in northern China are largely unknown. The main purposes of this study were to (1) assess the prevalence of depressive symptoms of HD patients in northern China, (2) explore demographic and clinical characteristics that might identify patients at high risk for depressive symptoms, (3) make comprehensive assessment by applying questionnaires of quality of life (QOL), social support, coping style, self-efficacy and ego resiliency, and try to find correlates of depressive symptoms of patients on HD.

\section{Methods}

A cross-sectional study was conducted by cluster sampling in two affiliated hospitals of China Medical University, from Dec 12, 2012 to Mar 15, 2013. Patients with CKD who received HD for at least one month participated in this study, and were face to face interviewed. Patients were interviewed while receiving dialysis treatments by medical students who were extensively and repeatedly trained by psychiatry faculty. All of the participants were well informed and had written informed consent. The study was approved by the Ethics Committee on Human Experimentation of The First Hospital of China Medical University.

The inclusion criteria for study participation were as follows: (1) age > 16 years; (2) ESRD patients who were undergoing HD therapy for at least one month; (3) had no history of transplant. The exclusion criteria were (1) younger than 16 years old; (2) patients with dementia or cognitive impairment which were defined by self or family report; (3) patients with unconsciousness or inability to read or write; (4) patients with severe complications of the heart, lung, brain and other parts of the body; (5) previous treatment for depression. There was no significant difference in age, sex and disease between excluded patients with depression and selected patients.

\section{Demographic and clinical characteristics}

Demographic characteristics included age, gender, marital status (married/others), educational level ( $\leq$ junior high school/> junior high school), financial status, HD duration and patient's functional status.

Data related to clinical characteristics, including cause of CKD, duration of renal disease, and ionic concentration were collected from hospital records. In addition, concern about arteriovenous fistula was also collected from patient interviews.

\section{Questionnaires}

\section{Measurement of depressive symptoms}

Chinese edition of the Center for Epidemiologic Studies Depression (CES-D) was used to measure depressive symptoms [17]. It includes 20 items, with each one comprising four categories: (0) never, (1) sometimes, (2) frequently and (3) always. Scores of 16 or more are defined as depressive symptomes. Participants were divided into groups of low and normal mood by score of 16 . It has been widely used in Chinese sample with satisfied validity and reliability (Cronbach's alpha was 0.8895).

\section{Measurement of functional status}

Activities of Daily Living Scale (ADL) was used to measure patient's functional status [18]. ADL, a 14-item selfrating scale can be categorized into basic $\mathrm{ADL}$ and instrumental ADL, which evaluated by six items (i.e. bathing, dressing, walking, toileting, tooth brushing and eating) and eight items (i.e. meal preparation, shopping, clothes washing, telephone using, finances managing, transferring, doing housework, and medicine taking) respectively [19]. Each item is scored on a 4-point scale, and higher score indicates a higher level of dependence. (Cronbach's alpha was 0.8709).

\section{Assessment of quality of life}

QOL was evaluated by using the 36-item Short-Form Health Survey (SF-36). The SF-36 measures eight different dimensions of health, which is described by a range from 0 to 100 in score, with a higher score indicating a better QOL. The accuracy of SF-36 using within Chinese HD patients has been confirmed previously (Cronbach's alpha was 0.9116) [20].

\section{Assessment of social support}

Perceived Social Support Scale (PSSS) was used to assess social support status. PSSS, containing 12 self-evaluating clauses, can be categorized into family support and outside family support. Each clause is scored from 1 (strongly disagree) to 7 (strongly agree), and higher score indicates a higher social support got by the participant. The reliability and validity of the Chinese Version of PSSS are satisfactory (Cronbach's alpha was 0.8792) [21, 22].

\section{Assessment of coping style}

Coping style was assessed by using the Chinese edition of Medical Coping Modes Questionnaire (MCMQ) [23]. It consists of 20 items, including three critical subscales: confrontation, avoidance, and acceptance-resignation. (Cronbach's alpha was 0.7268, 0.6345, and 0.6486, respectively). 


\section{Assessment of self-efficacy}

Self-efficacy was assessed by using the adapted General Self-efficacy Scale, which was evolved from the English version. It includes 10 items, and each item is scored on a 4-point scale, ranging from strong disagreement (1) to strong agreement (4), and higher score indicates a higher level of self-efficacy. The reliability of the scale is high (Cronbach's alpha was 0.9174).

\section{Assessment of ego resiliency}

Ego Resiliency Scale was used to assess ego resiliency [24]. It includes 14 items rated on a 4-point scale, ranging from low level (1) to high level (4), and higher score indicates a higher level of ego resiliency $[25,26]$. (Cronbach's alpha was 0.7868).

\section{Statistical analysis}

Continuous data are presented as means \pm standard deviations. Student's $t$-test was used to compare the means of normally distributed variables between "low mood" and "normal mood", and the Mann-Whitney U test was used for variables that were not normally distributed. Differences among categorical variables were analyzed by using chi-square test or two-tailed Fisher's exact test. Factors associated with depressive symptoms were determined by multivariate logistic regression analysis. The variables selected into the multivariable logistic model were the ones which were statistically significant, or had significant impacts on the result according to literature reports.

The Statistical Package for Social Sciences Version 11.5 (SPSS Inc., Chicago, IL, USA) was applied for statistical analysis, and the statistical significance was set at $P<0.05$ (two- tailed test).

\section{Results}

Description of demographic and clinical characteristics of patients

Of the 280 patients asked to participate in this study, 40 declined to participate with an $85.7 \%$ consent rate, and 13 were excluded for unqualified questionnaire with missing values exceeding $10 \%$. Finally, our study sample was comprised of 227 patients (female, 46.7\%; mean age, $49.3 \pm 14.3$ years, ranging from 17 to 85 years; duration of HD, mean 40 months, ranging from 1 to 103 months). Table 1 shows detailed data.

Other causes of ESRD not specified in Table 1 included chronic interstitial nephritis (8.8\%), polycystic kidney disease (4.8\%), renal allograft loss (3.5\%), lupus nephritis (2.2\%), purpura nephritis (1.8\%), HBV associated glomerulonephritis (1.8\%), gouty nephropathy $(1.3 \%)$, systemic vasculitis $(0.9 \%)$, obstructive nephropathy $(0.4 \%)$, trauma $(0.4 \%)$, and unknown causes $(4.9 \%)$.

\section{Description of the patients' depressive symptoms}

In our study, sixty-six patients (29.1\%) suffered from depressive symptoms. Table 1 shows the demographic characteristics of all participants. There was no significant difference between groups of low and normal mood in HD duration, marital status, educational level, religion, primary kidney disease or renal disease duration. Patients with depressive symptoms had lower monthly income and concerned more about arteriovenous fistula.

Table 1 also shows the scores of ADL, QOL, social support, coping style, self-efficacy and ego resiliency. Patients with a lower mood have worse ADL and QOL than patients with better mood. For both family support and outside family support, patients with a lower mood have got less social support than patients with better mood. Patients with a lower mood more inclined to choose "acceptance-resignation" coping style than patients with better mood, while the result is opposite in "avoidance" coping style. And patients with a better mood have better self-efficacy and ego resiliency than patients with lower mood.

\section{Multivariate logistic regression analysis for related factors} Multivariate logistic regression analyses revealed that $\mathrm{ADL}(\mathrm{OR}=1.124, p=0.002)$, family support $(\mathrm{OR}=0.867$, $p=0.021)$, "acceptance-resignation" coping style $(\mathrm{OR}=1.228, p=0.022)$, and ego resiliency $(\mathrm{OR}=0.944$, $p=0.021)$ were independently associated with low mood (Table 2).

\section{Discussion}

In our study, the prevalence of depressive symptoms in CKD patients on HD was $29.1 \%$. The result is consistent with previous data showing a prevalence of depression in patients on HD ranges from $23 \%$ to $45.9 \%$ [7, 8]. However, the result is a little higher than the prevalence of depression among pre-dialysis CKD patients [27, 28]. Compared with the population in developed countries, Chinese often feel embarrassed to seek mental health care because of the cultural issues, so that the mental health status of Chinese has been ignored for decades, and there are less studies focus on mental health of patients on HD [29, 30]. Therefore, summarizing the prevalence of depressive symptoms in patients on HD in northern China is an important first step, then developing additional research priorities [31].

Patients with a lower mood have worse ADL than patients with better mood. Also, ADL was associated with low mood independently. Our finding was in agreement with some previous studies [32]. Patients in ESRD struggled to carry out normal daily life despite the dependency caused by the illness [33]. The reality that they could not finish routine activities independently, such as bathing or doing housework may be associated with 
Table 1 Demographic characteristics of HD patients with low and normal mood

\begin{tabular}{|c|c|c|c|c|}
\hline & $\begin{array}{l}\text { Number of subjects } \\
n=227\end{array}$ & $\begin{array}{l}\text { Normal mood } \\
(\text { CES-D < 16) } \\
n=161\end{array}$ & $\begin{array}{l}\text { Low mood } \\
(\text { CES-D > =16) } \\
n=66\end{array}$ & $p$ value \\
\hline Gender, n (\%) & & & & 0.058 \\
\hline Male & $121(53.3 \%)$ & $85(52.8 \%)$ & $36(54.6 \%)$ & \\
\hline Female & $106(46.7 \%)$ & $76(47.2 \%)$ & $30(45.4 \%)$ & \\
\hline Age (years) $(\text { mean } \pm S D)^{a}$ & & $49.13 \pm 14.20$ & $49.65 \pm 14.60$ & 0.804 \\
\hline HD duration (months) & & & & 0.351 \\
\hline$\leq 24$ & $71(31.2 \%)$ & $54(33.5 \%)$ & $17(25.8 \%)$ & \\
\hline $25-60$ & $78(34.4 \%)$ & $56(34.8 \%)$ & $22(33.3 \%)$ & \\
\hline$>60$ & $78(34.4 \%)$ & $51(31.7 \%)$ & $27(40.9 \%)$ & \\
\hline Marital status, n (\%) & & & & 0.820 \\
\hline Married & $181(79.7 \%)$ & 129(80.1\%) & $52(78.8 \%)$ & \\
\hline others & $46(20.3 \%)$ & $32(19.9 \%)$ & $14(21.2 \%)$ & \\
\hline Educational level & & & & 0.922 \\
\hline$\leq$ Junior high school & $94(41.4 \%)$ & $67(41.6 \%)$ & $27(40.9 \%)$ & \\
\hline$>$ Junior high school & $133(58.6 \%)$ & $94(58.4 \%)$ & $39(59.1 \%)$ & \\
\hline Monthly income per person (Yuan) & & & & $0.008^{* *}$ \\
\hline$<800$ & $42(18.5 \%)$ & $25(15.5 \%)$ & $17(25.8 \%)$ & \\
\hline $800-1499$ & $49(21.6 \%)$ & $28(17.4 \%)$ & $21(31.8 \%)$ & \\
\hline 1500-2999 & $75(33.0 \%)$ & $58(36.0 \%)$ & $17(25.8 \%)$ & \\
\hline 3000-4999 & $39(17.2 \%)$ & $34(21.1 \%)$ & $5(7.6 \%)$ & \\
\hline$\geq 5000$ & $22(9.7 \%)$ & $16(9.9 \%)$ & $6(9.1 \%)$ & \\
\hline Primary kidney disease & & & & 0.445 \\
\hline Chronic glomerulonephritis & $116(51.1 \%)$ & $87(54.0 \%)$ & $29(43.9 \%)$ & \\
\hline Diabetic nephropathy & 19(8.4\%) & 13(8.1\%) & $6(9.1 \%)$ & \\
\hline Hypertension & $22(9.7 \%)$ & 13(8.1\%) & $9(13.6 \%)$ & \\
\hline Others & $70(30.8 \%)$ & $48(29.8 \%)$ & $22(33.3 \%)$ & \\
\hline $\mathrm{Ca}(\mathrm{mmol} / \mathrm{L})(\text { mean } \pm \mathrm{SD})^{\mathrm{a}}$ & & $2.11 \pm 0.30$ & $2.18 \pm 0.28$ & 0.074 \\
\hline $\mathrm{P}(\mathrm{mmol} / \mathrm{L})(\operatorname{median}(\mathrm{IQR}))^{\mathrm{b}, \mathrm{c}}$ & & $2.08(1.05)$ & $1.95(1.30)$ & 0.768 \\
\hline PTH $(\mathrm{pmol} / \mathrm{L})(\operatorname{median}(\mathrm{IQR}))^{\mathrm{b}, \mathrm{c}}$ & & $36.67(122.05)$ & $29.12(36.06)$ & 0.300 \\
\hline Total weekly urea Kt $/ \mathrm{N}(\text { mean } \pm \mathrm{SD})^{\mathrm{a}}$ & $1.4 \pm 0.5$ & $1.4 \pm 0.5$ & $1.4 \pm 0.5$ & 0.606 \\
\hline Religion & & & & 0.850 \\
\hline No & 198(87.2\%) & $140(87.0 \%)$ & $58(87.9 \%)$ & \\
\hline Yes & $29(12.8 \%)$ & $21(13.0 \%)$ & $8(12.1 \%)$ & \\
\hline BMI & & & & 0.155 \\
\hline$<25$ & $182(80.2 \%)$ & $125(77.6 \%)$ & $57(86.4 \%)$ & \\
\hline$\geq 25$ & $45(19.8 \%)$ & $36(22.4 \%)$ & $9(13.6 \%)$ & \\
\hline Concern about arteriovenous fistula & & & & $0.032^{*}$ \\
\hline Always & $67(29.5 \%)$ & $43(26.7 \%)$ & $24(36.4 \%)$ & \\
\hline Frequently & $37(16.3 \%)$ & $22(13.7 \%)$ & $15(22.7 \%)$ & \\
\hline Not at all & 123(54.2\%) & $96(59.6 \%)$ & $27(40.9 \%)$ & \\
\hline Renal disease duration (months) & & & & 0.382 \\
\hline$\leq 40$ & $71(31.3 \%)$ & $46(28.6 \%)$ & $25(37.9 \%)$ & \\
\hline $41-89$ & $82(36.1 \%)$ & $61(37.9 \%)$ & $21(31.8 \%)$ & \\
\hline$\geq 90$ & $74(32.6 \%)$ & $54(33.5 \%)$ & $20(30.3 \%)$ & \\
\hline
\end{tabular}


Table 1 Demographic characteristics of HD patients with low and normal mood (Continued)

\begin{tabular}{|c|c|c|c|}
\hline Activities of daily living & $15.4 \pm 3.9$ & $18.1 \pm 6.3$ & $<0.001^{* * *}$ \\
\hline \multicolumn{4}{|l|}{ SF-36 $(\text { mean } \pm \text { SD) })^{a}$} \\
\hline Physical functioning & $81.1 \pm 18.3$ & $67.7 \pm 24.4$ & $<0.001^{* * *}$ \\
\hline $\begin{array}{l}\text { Role limitation due to } \\
\text { physical problems }\end{array}$ & $53.1 \pm 40.7$ & $28.8 \pm 38.0$ & $<0.001^{* * *}$ \\
\hline Role limitation due to emotional problems & $78.9 \pm 32.6$ & $44.9 \pm 45.5$ & $<0.001^{* * *}$ \\
\hline Social functioning & $69.4 \pm 22.2$ & $47.3 \pm 24.8$ & $<0.001^{* *}$ \\
\hline Mental health & $85.7 \pm 12.8$ & $54.9 \pm 22.9$ & $<0.001^{* * *}$ \\
\hline Energy and vitality & $69.1 \pm 18.7$ & $42.8 \pm 21.0$ & $<0.001^{* *}$ \\
\hline Bodily pain & $82.4 \pm 25.7$ & $63.6 \pm 34.1$ & $<0.001^{* * *}$ \\
\hline General perception of health & $49.3 \pm 20.2$ & $29.1 \pm 16.9$ & $<0.001^{* *}$ \\
\hline \multicolumn{4}{|l|}{ Social support (mean $\pm \mathrm{SD})^{\mathrm{a}}$} \\
\hline Family support & $25.3 \pm 2.6$ & $23.5 \pm 3.6$ & $<0.001^{* * *}$ \\
\hline Outside family support & $44.5 \pm 8.9$ & $37.7 \pm 11.1$ & $<0.001^{* * *}$ \\
\hline \multicolumn{4}{|l|}{ Coping style $(\text { mean } \pm S D)^{a}$} \\
\hline Confrontation & $18.8 \pm 4.5$ & $17.9 \pm 4.5$ & 0.149 \\
\hline Avoidance & $18.1 \pm 3.3$ & $17.1 \pm 3.1$ & $0.041^{*}$ \\
\hline Acceptance-resignation & $10.6 \pm 1.9$ & $11.9 \pm 2.3$ & $<0.001^{* * *}$ \\
\hline Self-efficacy (mean \pm SD) $)^{a}$ & $29.7 \pm 6.7$ & $24.4 \pm 7.6$ & $<0.001^{* * *}$ \\
\hline Ego resiliency $(\text { mean } \pm S D)^{a}$ & $41.1 \pm 7.9$ & $36.4 \pm 6.9$ & $<0.001^{* * *}$ \\
\hline
\end{tabular}

${ }^{*} p<0.05 ;{ }^{* *} p<0.01 ;{ }^{* * *} p<0.001$

${ }^{a}$ Independent-samples t test

b Median and inter-quartile range

c Mann-Whitney U test

Table 2 The multivariate logistic regression analysis for exploring factors of depressive symptoms

\begin{tabular}{llll}
\hline Variables & OR & OR 95\%Cl & $p$ value \\
\hline Age & 0.990 & $0.963 \sim 1.017$ & 0.457 \\
$\begin{array}{l}\text { Gender } \\
\text { (male vs. female) }\end{array}$ & 0.798 & $0.379 \sim 1.680$ & 0.552 \\
Activities of daily living & 1.124 & $1.043 \sim 1.212$ & $0.002^{* *}$ \\
Social support & & & \\
$\quad$ Family support & 0.867 & $0.768 \sim 0.979$ & $0.021^{*}$ \\
$\quad$ Outside family support & 0.972 & $0.935 \sim 1.010$ & 0.148 \\
Coping style & & & \\
$\quad$ Confrontation & 0.980 & $0.903 \sim 1.062$ & 0.619 \\
$\quad$ Aviodance & 0.966 & $0.861 \sim 1.084$ & 0.558 \\
$\quad$ Acceptance-resignation & 1.228 & $1.030 \sim 1.466$ & $0.022^{*}$ \\
Self-efficacy & 0.965 & $0.914 \sim 1.019$ & 0.202 \\
$\begin{array}{l}\text { Ego resiliency } \\
\text { HD duration (months) }\end{array}$ & 0.944 & $0.899 \sim 0.991$ & $0.021^{*}$ \\
$\begin{array}{l}>60 \text { vs. } \leq 24) \\
\text { HD duration (months) }\end{array}$ & 2.154 & $0.860 \sim 5.395$ & 0.101 \\
$(25-60$ vs. $\leq 24)$ & 1.182 & $0.486 \sim 2.878$ & 0.712 \\
* $p<0.05 ;$ ** $p<0.01$ & & & \\
\hline
\end{tabular}

depressive symptoms. In a research among 5763 patients on HD, the findings showed that aerobic physical activity was associated with fewer depression symptoms [34]. Finding some effective physical activity regimens which were suitable for Chinese HD people to improve the functional status may be a feasible scheme to reduce depressive symptoms in patients under HD treatment.

In our study, we found that patients with a lower mood received less social support than patients with better mood, including both family support and outside family support. And family support was negatively associated with low mood. Our finding was in agreement with previous study in patients on peritoneal dialysis (PD) in southern China [35]. Social support refers to the perception and actuality that one gets assistance from other people [36]. HD as a long-term management strategy, patients under HD treatment may lose personal freedom and social connectedness [37]. The characteristic of HD treatment changes the life style of family caregivers too. It is important that not only for the patients, but also for the family members to focus on preparation for the change to the new way of life [38]. According to our result, family support is associated with low mood, the support received from family is more important to the patients under HD treatment. For example, patients 
relied on spouses and siblings for help with transportation to and from the dialysis unit, and discussed with them the difficulties associated with $\operatorname{HD}[39,40]$. As family support is highly valued, the family members should give more advice and help.

In assessing the coping style, patients with a lower mood more like to select "acceptance-resignation" coping style than patients with better mood. And "acceptance-resignation" coping style was associated with low mood independently. This result was in agreement with previous study in patients on peritoneal dialysis (PD) in southern China [35]. Patients on HD must confront with constant threat of diseases and death, which will impose them many challenges and difficulties, and will often require new and different ways to cope with. This result suggested that patients with low mood were inclined to the usage of "acceptance-resignation" coping style. Use of this type of coping style indicates a lack of hope, shows that patients under HD regard their disease as non-solving, so it is not surprising that "acceptance-resignation" coping style are associated with low mood in patients on HD.

In our study, we also found that patients with a better mood have better ego resiliency than patients with lower mood. And ego resiliency was independently associated with low mood. Ego resiliency is an individual's ability to adapt to stress and adversity. Individuals with better ego-resiliency are likely to adjust well to changing environment [41]. Thus, physicians should evaluate egoresiliency of HD patients, and help them developing ego-resiliency may moderate the happening of the depressive symptoms.

We could speculate on the situation of the whole population according to results of this study, based on the property of cluster sampling. However, several limitations of our study should be considered. First, patients recruited in our study were only from two affiliated hospitals which may limit to public hospitals in city. Second, since this study is a cross-sectional study, we couldn't get causality based on our findings, further longitudinal studies with treatment interventions is necessary.

\section{Conclusions}

In conclusion, based on cross-sectional survey, our findings revealed that in HD patients in northern China, the prevalence of depressive symptoms was high. ADL, family support, "acceptance-resignation" coping style and ego resiliency were independently associated with depressive symptoms. Physicians should give more attention to prevent and treat depressive symptoms among HD patients.

\section{Acknowledgments}

The authors wish to thank the dialysis nurses and doctors at the participating dialysis units: Department of Nephrology, The First Hospital of China Medical University, and Department of Nephrology, General Hospital of Fushun Mining Bureau.

\section{Funding}

This study was supported by grant from Ministry of Health (No. 2011BAl10B02), Chinese Society of Nephrology (No. 13030320417) and Scientific research of The First Hospital of China Medical University.

\section{Availability of data and materials}

The data will not be made available in order to protect the participants identity.

\section{Authors' contributions}

$X L, X Y, L Y, Q Z$ and $L W$ contributed to designing and conducting the study; $X L$ drafted the manuscript; $X Y$ contributed to analysis and interpretation of data; DS, XZ, TX, and QL contributed to acquisition of data. All authors reviewed and have approved the final manuscript.

\section{Competing interests}

The authors declare that they have no competing interests.

Consent for publication

Not applicable.

\section{Ethics approval and consent to participate}

The study was approved by the Ethics Committee on Human Experimentation of The First Hospital of China Medical University (Ethical approval No. [2015]2015-112-2). All of the participants were well informed about the content and the aim of the questionnaire. All surveys were conducted after obtaining written consent from the participants.

\section{Statement}

The authors adhered to STROBE guidelines/methodology.

\section{Publisher's note}

Springer Nature remains neutral with regard to jurisdictional claims in published maps and institutional affiliations.

\section{Author details}

${ }^{1}$ Department of Nephrology, The First Hospital of China Medical University, No.155 North Nanjing Street, Shenyang, Liaoning, People's Republic of China 110001. 'Department of Social Medicine, School of Public Health, China Medical University, No.77 Puhe Road, Shenyang North New Area, Shenyang, Liaoning, People's Republic of China110013. ${ }^{3}$ Department of Nephrology, General Hospital of Fushun Mining Bureau, No.24, Zhongyang Ave., Xinfu Dist. Fushun, Liaoning, People's Republic of China113008.

Received: 3 August 2016 Accepted: 31 March 2017

Published online: 05 April 2017

\section{References}

1. Yu X, Yang X. Peritoneal dialysis in China: meeting the challenge of chronic kidney failure. Am J Kidney Dis. 2015;65(1):147-51.

2. Zhang L, Wang F, Wang L, Wang W, Liu B, Liu J, et al. Prevalence of chronic kidney disease in China: a cross-sectional survey. Lancet. 2012;379(9818): 815-22.

3. Zuo L, Wang M. Chinese Association of Blood Purification Management of Chinese hospital association. Current burden and probable increasing incidence of ESRD in China. Clin Nephrol. 2010;74(Suppl 1):S20-2.

4. Liu ZH. Nephrology in china. Nat Rev Nephrol. 2013;9(9):523-8.

5. Zhang ZZ, Zhao K. The report of dialysis assessment and payment for endstage renal disease in China. National Health Development Research Center: Beijing; 2011.

6. Al Zaben F, Sehlo MG, Khalifa DA, Al Shohaib S, Shaheen F, Alzaben L, et al. Prospective study of depression among dialysis patients in Saudi Arabia. Int Urol Nephrol. 2015:47(6):1001-10.

7. Fan L, Sarnak MJ, Tighiouart H, Drew DA, Kantor AL, Lou KV, et al. Depression and all-cause mortality in hemodialysis patients. Am J Nephrol. 2014;40(1):12-8

8. Hung KC, Wu CC, Chen HS, Ma WY, Tseng CF, Yang LK, et al. Serum IL-6, albumin and co-morbidities are closely correlated with symptoms of depression in patients on maintenance haemodialysis. Nephrol Dial Transplant. 2011;26(2):658-64. 
9. Lopes AA, Bragg J, Young E, Goodkin D, Mapes D, Combe C, Piera L, Held P, Gillespie B, Port FK. Dialysis outcomes and practice patterns study (DOPPS). Depression as a predictor of mortality and hospitalization among hemodialysis patients in the United States and Europe. Kidney Int. 2002;62(1):199-207.

10. Hedayati SS, Bosworth HB, Briley LP, Sloane RJ, Pieper CF, Kimmel PL, Szczech LA. Death or hospitalization of patients on chronic hemodialysis is associated with a physician-based diagnosis of depression. Kidney Int. 2008; 74(7):930-6.

11. Friedli K, Guirguis A, Almond M, Day C, Chilcot J, Da Silva-Gane M, Davenport A, Fineberg NA, Spencer B, Wellsted D, Farrington K. Sertraline versus placebo in patients with major depressive disorder undergoing Hemodialysis: a randomized, controlled feasibility trial. Clin J Am Soc Nephrol. 2017;12(2):280-6.

12. Lorant V, Deliege D, Eaton W, Robert A, Philippot P, Ansseau M. Socioeconomic inequalities in depression: a meta-analysis. Am J Epidemiol. 2003;157(2):98-112.

13. Weisbord SD, Mor MK, Sevick MA, Shields AM, Rollman BL, Palevsky PM, et al. Associations of depressive symptoms and pain with dialysis adherence, health resource utilization, and mortality in patients receiving chronic hemodialysis. Clin J Am Soc Nephrol. 2014;9(9):1594-602.

14. Riezebos RK, Nauta KJ, Honig A, Dekker FW, Siegert CE. The association of depressive symptoms with survival in a Dutch cohort of patients with endstage renal disease. Nephrol Dial Transplant. 2010;25(1):231-6.

15. Agganis BT, Weiner DE, Giang LM, Scott T, Tighiouart $H$, Griffith $J$, et al. Depression and cognitive function in maintenance hemodialysis patients. Am J Kidney Dis. 2010;56(4):704-12.

16. Lacson Jr E, Li NC, Guerra-Dean S, Lazarus M, Hakim R, Finkelstein FO. Depressive symptoms associate with high mortality risk and dialysis withdrawal in incident hemodialysis patients. Nephrol Dial Transplant. 2012;27(7):2921-8.

17. Radloff LS. The CES-D scale a self-report depression scale for researching the general population. Appl Psychol Meas. 1977;1:385-401.

18. Lawton MP, Brody EM. Assessment of older people: self-maintaining and instrumental activities of daily living. Gerontologist. 1969;9(3):179-86.

19. Wang L, Yang X, Hou Z, Feng Q, Wanjing Y. Application and evaluation of Chinese version of Zarit burden interview. Chin J Public Health. 2006;22:970-2.

20. Li L, Wang HM, Shen Y. Chinese SF-36 health survey: translation, cultural adaptation, validation, and normalisation. J Epidemiol Community Health. 2003;57(4):259-63.

21. Huang L, Jiang QJ, Reng WH. Coping style, social support, and psychosomatic symptoms in patients with cancer. Chin Ment Health J. 1996;10:160-1.

22. Fang JQ. Perceiving social support scale. Chin J Behav Med Sci. 2001;10:41-2.

23. Feifel H, Strack S, Nagy VT. Coping strategies and associated features of medically ill patients. Psychosom Med. 1987;49(6):616-25.

24. Block JH, Block J. The role of ego-control and ego-resiliency in the organization of behavior. In: Collins WA, editor. Development of cognition, affect, and social relations: the Minnesota symposia on child psychology, vol. 13. Hillsdale, NJ: Erlbaum; 1980

25. Block J, Kremen AM. IQ and ego-resiliency: conceptual and empirical connections and separateness. J Pers Soc Psychol. 1996;70(2):349-61.

26. Klohnen EC. Conceptual analysis and measurement of the construct of egoresiliency. J Pers Soc Psychol. 1996;70(5):1067-79.

27. Hedayati SS, Minhajuddin AT, Toto RD, Morris DW, Rush AJ. Prevalence of major depression episode in CKD. Am J Kidney Dis. 2009;54(3):424-32.

28. Sumanathissa M, De Silva VA, Hanwella R. Prevalence of major depressive episode among patients with pre-dialysis chronic kidney disease. Int J Psychiatry Med. 2011;41(1):47-56.

29. Jeon HJ, Walker RS, Inamori A, Hong JP, Cho MJ, Baer L, et al. Differences in depressive symptoms between Korean and American outpatients with major depressive disorder. Int Clin Psychopharmacol. 2014;29(3):150-6.

30. Chen AW, Kazanjian A, Wong H. Why do Chinese Canadians not consult mental health services: health status, language or culture? Transcult Psychiatry. 2009;46(4):623-41.

31. Palmer S, Vecchio M, Craig JC, Tonelli M, Johnson DW, Nicolucci A, et al. Prevalence of depression in chronic kidney disease: systematic review and meta-analysis of observational studies. Kidney Int. 2013;84(1):179-91.

32. Zhang M, Kim JC, Li Y, Shapiro BB, Porszasz J, Bross R, et al. Relation between anxiety, depression, and physical activity and performance in maintenance hemodialysis patients. J Ren Nutr. 2014;24(4):252-60.

33. Gilbar O, Or-Han K, Plivazky N. Mental adjustment, coping strategies, and psychological distress among end-stage renal disease patients. J Psychosom Res. 2005;58(6):471-6.
34. Lopes AA, Lantz B, Morgenstern H, Wang M, Bieber BA, Gillespie BW, et al. Associations of self-reported physical activity types and levels with quality of life, depression symptoms, and mortality in hemodialysis patients: the DOPPS. Clin J Am Soc Nephrol. 2014;9(10):1702-12.

35. Lin J, Guo Q, Ye X, Li J, Yi C, Zhang X, et al. The effect of social support and coping style on depression in patients with continuous ambulatory peritoneal dialysis in southern China. Int Urol Nephrol. 2013;45(2):527-35.

36. McKercher C, Sanderson K, Jose MD. Psychosocial factors in people with chronic kidney disease prior to renal replacement therapy. Nephrology (Carlton). 2013;18(9):585-91.

37. Thong MS, Kaptein AA, Krediet RT, Boeschoten EW, Dekker FW. Social support predicts survival in dialysis patients. Nephrol Dial Transplant. 2007; 22(3):845-50.

38. Monaro S, Stewart G, Gullick J. A 'lost life': coming to terms with haemodialysis. J Clin Nurs. 2014:23(21-22):3262-73.

39. Mok E, Lai C, Zhang ZX. Coping with chronic renal failure in Hong Kong. Int J Nurs Stud. 2004:41(2):205-13.

40. Al Nazly E, Ahmad M, Musil C, Nabolsi M. Hemodialysis stressors and coping strategies among Jordanian patients on hemodialysis: a qualitative study. Nephrol Nurs J. 2013;40(4):321-7. quiz 328

41. Milioni M, Alessandri G, Eisenberg N, Castellani V, Zuffianò A, Vecchione M, et al. Reciprocal relations between emotional self-efficacy beliefs and egoresiliency across time. J Pers. 2015;83(5):552-63.

\section{Submit your next manuscript to BioMed Central and we will help you at every step:}

- We accept pre-submission inquiries

- Our selector tool helps you to find the most relevant journal

- We provide round the clock customer support

- Convenient online submission

- Thorough peer review

- Inclusion in PubMed and all major indexing services

- Maximum visibility for your research

Submit your manuscript at www.biomedcentral.com/submit
) Biomed Central 